Acknowledgments: None

Disclosure of Interests: None declared

DOI: 10.1136/annrheumdis-2020-eular.3533

\section{FRI0197 THE DIAGNOSTIC ACCURACY OF VASCULAR ULTRASOUND IN PATIENTS SUSPECTED OF GCA A DANISH MULTICENTRE PROSPECTIVE COHORT STUDY}

S. Chrysidis ${ }^{1,2,3}$, U. Møller Døhn ${ }^{4}$, L. Terslev ${ }^{4}$, U. Fredberg ${ }^{2,5}$, T. Lorenzen $^{5}$, R. Christensen ${ }^{2,3}$, P. Søndergaard ${ }^{5}$, J. Matthisson ${ }^{1}$, K. Larsen ${ }^{1}$,

A. Diamandopoulos ${ }^{6} .{ }^{1}$ Hospital of Southwest Jutland, Esbjerg, Denmark; ${ }^{2}$ University of Southern Denmark, Denmark; ${ }^{3}$ The Parker Institute, Copenhagen, Denmark; ${ }^{4}$ Rigshospitalet, Glostrup and COPECARE, Copenhagen, Denmark; ${ }^{5}$ Silkeborg Regional Hospital, Silkeborg, Denmark; ${ }^{6}$ Martina Hansens Hospital, Baerum, Norway

Background: Giant Cell Arteritis (GCA) is one of the most common systemic vasculitis. Temporal artery biopsy (TAB) has been the standard test to confirm the diagnosis of GCA. However, TAB has a lower sensitivity than clinical diagnosis and up to $44 \%$ of biopsy-negative patients are clinically diagnosed as having GCA. In a recent meta-analysis of the diagnostic performance of ultrasound (US) in GCA the sensitivity was $77 \%$ (1). The included studies were performed by expert groups in single centres. In the to date only multicentre study (TABUL) investigating the diagnostic accuracy of US compared to clinical diagnosis after 6 months the sensitivity was lower (54\%) (2)

Objectives: To evaluate the diagnostic accuracy of vascular US compared to TAB in a multicentre study.

Methods: In three Danish centres patients suspected for GCA were included during a period of two years. At baseline, clinical and laboratory data were collected and vascular US of temporal, facial, common carotid and axillary artery were performed. The US examinations were performed with high frequency transducers (15-18 MHZ) and followed by a TAB. All ultrasongraphers had participated in the same standardized US educational program and were blinded to clinical and laboratory data. An external expert blinded to clinical and laboratory data evaluated all images and made the final US diagnosis.

A positive sign for vasculitis in cranial arteries was defined as a hypoechoic intima media complex (IMC) thickening (halo sign) and a positive compression sign. A homogeneous IMC increased thickness in axillary artery of $\geq 1 \mathrm{~mm}$ and in common carotid artery $\geq 1.5 \mathrm{~mm}$ was defined as vasculitis.

The consultant rheumatologist's diagnosis at 6 months after initial presentation was considered as the reference standard for the diagnosis of GCA

Results: During the recruitment period, 112 patients were included, $59 \%$ females, mean (SD) age 72.4(7.9) years, among which 91(81.3\%) fulfilled the ACR 1990 classification criteria for GCA. $92 \%$ of the patients reported a newly emerged localized headache, while $49(43.8 \%)$ experienced polymyalgia rheumatic symptoms. TAB was positive in $46(41.1 \%)$ and inconclusive in 6 patients, who were excluded from the analysis. Mean (SD) duration of glucocorticoid therapy prior to US and TAB was $0.91(1.55)$ and 4.02(2.61) days, respectively. In 62 patients, the final diagnosis was GCA.

In all patients with a positive TAB, the US of the temporal artery was also positive for GCA. Of 19 cases with positive US and negative TAB, 12 were clinically diagnosed with GCA of whom 6 had isolated large vessel involvement on US. Among 41 patients with both negative US and TAB, 4 were clinically diagnosed with GCA (Box 1)

US had a sensitivity of $93 \%$ and specificity of $84 \%$ for the diagnosis of GCA, while the sensitivity for TAB was lower $(74 \%)$ with a specificity of $100 \%$. For the diagnosis of GCA, US had a PPV of $89.2 \%$ and a NPV of $90.2 \%$, while for TAB the PPV was $100 \%$ and the NPV $73.3 \%$

Conclusion: US evaluation of the temporal, facial and selected supraaortic arteries performed by trained ultrasonographers can replace biopsy in the diagnosis of GCA.

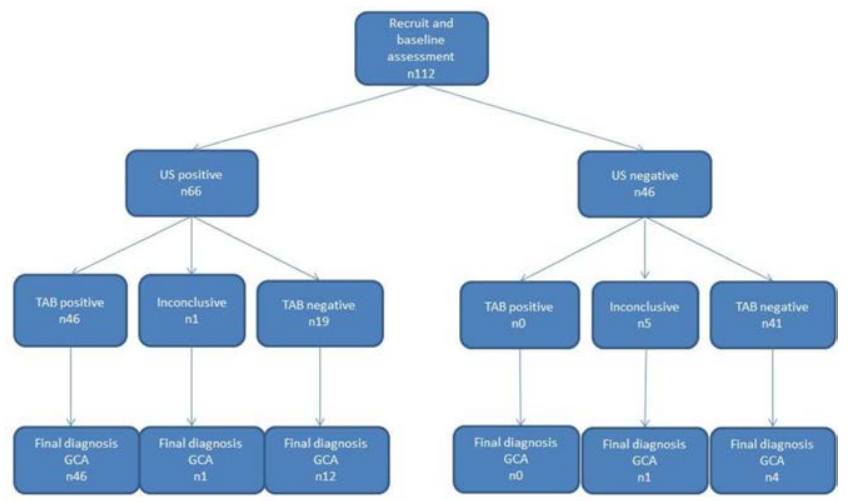

\section{References:}

[1] Duftner C, Dejaco C, et al. Imaging in diagnosis, outcome prediction and monitoring of large vessel vasculitis: a systematic literature review and metaanalysis informing the EULAR recommendations. RMD Open 2018;4:e000612.

[2] Luqmani $R$ et al. The Role of Ultrasound Compared to Biopsy of Temporal Arteries in the Diagnosis and Treatment of Giant Cell Arteritis (TABUL): a diagnostic accuracy and cost-effectiveness study. Health Technol Assess 2016;20:1_238.

Disclosure of Interests: stavros chrysidis: None declared, Uffe Møller Døhn: None declared, Lene Terslev Speakers bureau: LT declares speakers fees from Roche, MSD, BMS, Pfizer, AbbVie, Novartis, and Janssen., Ulrich Fredberg: None declared, Tove Lorenzen: None declared, Robin Christensen: None declared, Per Søndergaard: None declared, Jakob Matthisson: None declared, Knud Larsen: None declared, Andreas Diamandopoulos: None declared DOI: 10.1136/annrheumdis-2020-eular.3953

\section{FRI0198 OCULAR MORBIDITY IN PATIENTS WITH PMR AND GCA IN THE UK - A CPRD STUDY}

M. Yates ${ }^{1,2}$, A. Clark ${ }^{1}$, R. Watts ${ }^{2}$, A. Macgregor ${ }^{1}$, S. Mackie ${ }^{3}$ on behalf of Dr Max Yates is part of the TARGET (Treatment According to Response in Giant ceLL arTeritis) consortium, the UK BioBank Eye and Vision Consortium and an active member of two OMERACT (Outcome Measures in Rheumatology) Working Groups: PMR and Patient Outcomes in Longitudinal Observational Studies. ${ }^{1}$ University of East Anglia, Norwich Medical School, Norwich, United Kingdom; ${ }^{2}$ Ipswich Hospital, Rheumatology, Ipswich, United Kingdom; ${ }^{3}$ Chapel Allerton Hospital, Rheumatology, Leeds, United Kingdom

Background: Visual loss is the most serious consequences of a diagnosis of polymyalgia rheumatic (PMR) and giant cell arteritis (GCA). To date, information on the occurrence of eye disease in GCA has been based almost exclusively on small hospital-based patient series. Furthermore the lack of control group for these studies results in a lack of relative risk estimates for visual loss.

There are no accurate data on the prevalence and nature of eye complications among patients in the community. Patients with GCA may be exclusively managed in the primary care setting without referral for either temporal artery biopsy or ophthalmic department examination. Currently the incidence and prevalence of eye complications within this group are unknown.

Objectives: Examine the absolute rate and relative risk of ocular morbidity, in a longitudinal community setting, in patients with PMR and or GCA including visual loss, AOIN including optic atrophy, cataract and glaucoma identified from Read codes in the (Clinical Practice Research Datalink) CPRD dataset.

Methods: Construction of a disease cohort of incident diagnoses of PMR and GCA from patients in the CPRD matched to controls on age, sex ( $+/-2$ years) and practice location. Diagnosis were identified by CPRD researchers of those individuals between January 1997 to December 2015, with a minimum age at diagnosis of 50 years. Those with both a diagnosis of PMR and GCA were analysed in the GCA group. The outcomes of ocular morbidity included Read codes for severe visual impairment (multiple codes covered: blindness, severe visual impairment, registered partially sighted, issue of certificate of visual impairment, examination findings of $4 / 60$ or worse), anterior ischaemic optic neuropathy (including codes of optic neuropathy and atrophy but not codes of glaucomatous atrophy), cataract, cataract extraction and glaucoma. Statistically modelling with Cox proportional hazards was used to generate hazard ratios for ocular morbidity taking account of censorship through death and moving out of area.

Results: We identified 30,714 individuals with PMR (20,270 women; $66 \%$ ) with a mean age at diagnosis of 72.9 year (sd 9.1) and 6,104 with GCA $(4,309$ women; $70.6 \%$ ) with a mean age of 72.1 years (sd 9.4). Of those diagnosed with GCA 1,669 were also diagnosed with PMR. Using Read codes for severe visual impairment and blindness $5.9 \%$ of patients with GCA and $2.7 \%$ with PMR had this complication compared with $1.6 \%$ of the matched controls. The hazard ratio for the various ocular morbidities and by cases of PMR or GCA are shown in the table below:

\begin{tabular}{lcc}
\hline Ocular morbidity & PMR HR $(95 \% \mathrm{Cl}) \mathrm{p}$ value & GCA HR $(95 \% \mathrm{Cl}) \mathrm{p}$ value \\
\hline Severe visual impairment & $1.76(1.60,1.94) \mathrm{p}=<0.001$ & $3.55(3.10,4.08) \mathrm{p}=<0.001$ \\
Anterior ischaemic optic atrophy & $3.37(2.15,5.31) \mathrm{p}=<0.001$ & $36.33(25.19,52.39) \mathrm{p}=<0.001$ \\
Cataract & $2.18(2.04,2.32) \mathrm{p}=<0.001$ & $2.48(2.22,2.78) \mathrm{p}=<0.001$ \\
Cataract operation & $2.11(1.97,2.25) \mathrm{p}=<0.001$ & $2.41(2.13,2.72) \mathrm{p}=<0.001$ \\
Glaucoma & $2.10(1.91,2.32) \mathrm{p}=<0.001$ & $2.50(2.10,2.97) \mathrm{p}=<0.001$ \\
\hline
\end{tabular}

Conclusion: These community-based national data on risk of ocular morbidity in PMR and GCA show for the first time the risk of various ocular morbidities are increased for both groups. In addition this are the first estimates of relative risk compared to an age and sex matched population. These data are crucial 
for providing information to patients about their relative risk of ocular morbidity following a diagnosis of PMR or GCA.

Acknowledgments: We would like to thank Dr Helen Strongman at the CPRD for carrying out patient searchers. We thank Dr Ferran Espuny Pujol for completion of the linkage request for dates of death.

Disclosure of Interests: Max Yates: None declared, Allan Clark: None declared, Richard Watts: None declared, Alex MacGregor: None declared, Sarah Mackie Grant/research support from: Roche (attendance of EULAR 2019; co-applicant on research grant), Consultant of: Sanofi, Roche/Chugai (monies paid to my institution not to me)

DOI: 10.1136/annrheumdis-2020-eular.4402

\begin{tabular}{|l|l|}
\hline FRI0199 & PRESENCE AND DISTRIBUTION OF VASCULITIS \\
IN TEMPORAL, AXILLARY AND SUBCLAVIAN \\
ARTERIES IN GIANT CELL ARTERITIS ASSESSED \\
BY ULTRASONOGRAPHY AT ONSET OF \\
DIAGNOSIS
\end{tabular}

P. M. Andel ${ }^{1}$, S. Brådland ${ }^{1}$, V. Haraldstad ${ }^{1}$, H. Bitter ${ }^{1}$, A. Diamantopoulos ${ }^{2}$, G. Haugeberg ${ }^{1,3}$. 'S Sørlandet Hospital Kristiansand, Kristiansand, Norway; ${ }^{2}$ Martina Hansens Hospital, Bærum, Norway; ${ }^{3}$ Norwegian University of Science and Technology, Trondheim, Norway

Background: In the last two decades ultrasound (US) has become a significant and valuable mode of diagnosing giant cell arteritis (GCA) in clinical practice (1). This is also reflected in the suggested expansion of the ACR 1990 criteria where imaging including US is equated with biopsy (2). Favorable sensitivity compared to biopsy has been shown and explained with the widespread uneven distribution of inflammation in cranial and extracranial arteries (3).

Objectives: To explore the prevalence and distribution of inflammatory involvement in temporal, axillary and subclavian arteries in patients diagnosed with GCA at an ordinary rheumatology clinic.

Methods: In this retrospective study we identified all patients diagnosed with GCA between 2006 and 2019. Since 2006 US has been used at the clinic to diagnose GCA. The vascular US examination was performed by two experienced ultrasonographers (HB, APD). The medical records were reviewed and data were collected using a predefined protocol including data collection for US at the time of diagnosis. Standard US procedure contained an assessment of both temporal arteries (superficial artery, frontal artery and parietal artery) in longitudinal and transversal planes with and without colordoppler mode. A positive US test was defined in presence of hypoechoic vessel wall thickening (halo sign). The axillary and subclavian arteries where assessed in B-mode and intima media thickness (IMT) was measured. A positive test was defined if $\mathrm{IMT}>1 \mathrm{~mm}$.

Results: A total of 69 GCA patients (20 men and 49 women) with US performed at the time of diagnosis were identified. Among them, 67 (97.1\%) patients met the suggested expansion ACR 1990 criteria. The mean age was 69.9 years. Detailed results for vasculitis distribution for the temporal artery with its branches and the axillary and subclavian arteries are shown in the table below. Positive US findings were recorded in 61 patients $(88.4 \%)$. A total of 45 patients $(65.2 \%)$ had a positive US test in the temporal artery and 41 patients $(59.4 \%)$ in the extracranial arteries. Solely extracranial arteritis was observed in 18 patients (29.5\%), 22 $(36.0 \%)$ had exclusively temporal involvement. Involvement of both cranial and extracranial arteries was observed in 21 patients (34.4\%). Only nine patients had positive findings at just one site. Five patients had isolated unilateral subclavian affection, and two patients had isolated unilateral frontal artery and superficial artery involvement each.

Table. Positive US finding in 69 GCA patients

\begin{tabular}{|c|c|c|c|c|c|}
\hline & \multicolumn{2}{|c|}{ Extracranial arteries } & \multicolumn{3}{|c|}{ Temporal arteries } \\
\hline & Subclavian & Axillary & Superficial & Parietal & Frontal \\
\hline Right side & 13 & 36 & 19 & 20 & 32 \\
\hline Left side & 13 & 27 & 18 & 18 & 32 \\
\hline total & 15 & 38 & 22 & 20 & 40 \\
\hline total & \multicolumn{2}{|c|}{41} & \multicolumn{3}{|c|}{45} \\
\hline
\end{tabular}

Conclusion: Our data highlights the importance and value of a complete US of cranial and extracranial arteries diagnosing GCA in daily clinical care. The data demonstrate the widespread nature of arterial affection in GCA and the fact that it is often more than one site that is affected. The spreading pattern was comparable to older studies in the respect of large vessel and multisite involvement

References:

[1] Dejaco C. et al. Ann Rheum Dis. 2018;77:636-43.
[2] Dejaco C et al. Rheumatology 2017;56:505-15.

[3] Schmidt W A. Rheumatology. 2018;57;ii22-ii31.

Disclosure of Interests: Peter Michael Andel Grant/research support from: Travel Grant from Vest Agder Legeforening, Norge, Serina Brådland: None declared, Vilde Haraldstad: None declared, Helle Bitter: None declared, Andreas Diamantopoulos: None declared, Glenn Haugeberg: None declared DOI: 10.1136/annrheumdis-2020-eular.5457

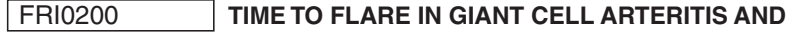 POLYMYALGIA RHEUMATICA AND REVIEW OF THE LITERATURE}

M. Bhurani ${ }^{1}$, S. Hall ${ }^{2,3}$, A. Ostor ${ }^{2,3}$, A. Gibson ${ }^{2} .{ }^{1}$ Monash University, Faculty of Medicine, Nursing and Health Sciences, Melbourne, Australia; ${ }^{2}$ Cabrini Hospital, Rheumatology, Melbourne, Australia; ${ }^{3}$ Emeritus Research, Camberwell, Australia

Background: Giant cell arteritis (GCA) and polymyalgia rheumatica (PMR) are two closely related inflammatory rheumatic diseases of the elderly. While glucocorticoid treatment leads to a dramatic initial improvement, the course of the diseases remains unpredictable and multifarious. Flare and relapses are common, however, data on this is limited ${ }^{[1][2]}$

Objectives: We set out to evaluate the flare rate, time to first flare and steroid dose during flare of patients diagnosed with GCA and PMR in our practice. The aim was to identify optimal timing for clinical review and contribute towards best practice.

Methods: A total of 218 patients diagnosed with GCA (38) and PMR (180) seen between 2015 and 2020 were audited. Demographic data was collected. Relapse rate, time to initial flare and steroid dose during flares were the primary endpoints for our analysis. Steroid sparing agent use was also documented.

Results: Our cohort comprised of 38 GCA patients $(M=15 ; F=23)$ and 180 PMR patients $(M=71 ; F=99)$ who were diagnosed between January 2015 and January 2020.The mean age of diagnosis for patients with GCA and PMR was 73 years and 71 years respectively. 10 patients (4.6\%) with PMR later progressed to develop Rheumatoid Arthritis and hence, were excluded from subsequent analyses. Most patients received an initial treatment of corticosteroid therapy for both diseases with a mean dose of $39.74 \mathrm{mg}$ for GCA and $18.23 \mathrm{mg}$ for PMR. During a mean follow up time of 13.8 months, 75 patients $(36 \%)(G C A=6$; PMR $=69)$ experienced at least one flare which was determined by clinical diagnosis either by unremitting reversion of initial symptoms and/or elevated inflammatory markers. While 13 patients $(6 \%)$ $(G C A=2 ; P M R=11)$ had a flare following completion of initial steroid therapy, 62 patients $(30 \%)(G C A=4 ; P M R=58)$ experienced flares during steroid tapering, the mean steroid dose observed during disease flare for the latter was $5.25 \mathrm{mg}$ for GCA and 4.67 for PMR. Majority of relapses/flares for PMR patients occurred within the first year of diagnosis (mean $=8.38$ months) and after the first year of diagnosis in GCA patients (mean = 15 months). Methotrexate was the most common traditional DMARD trialed as a steroid sparing alternative $(G C A=4 ; P M R=23)$ mostly introduced post flare/relapse. The mean appointment intervals for flares/relapses in our cohort was noticed to be during the $5^{\text {th }}$ and $6^{\text {th }}$ scheduled clinical review for GCA and between the $3^{\text {rd }}$ and $4^{\text {th }}$ clinical review for PMR patients.

Conclusion: A flaring and relapsing course is common to both GCA and PMR especially during steroid dose tapering. Increased clinical surveillance and more gradual steroid tapering, particularly at the time when most flares/relapses are observed may help improve clinical outcomes and reduce glucocorticoid requirements in patients.

References:

[1] Martinez-Lado L, Calviño-Díaz C, Piñeiro A, Dierssen T, Vazquez-Rodriguez $\mathrm{T}$, Miranda-Filloy $\mathrm{J}$ et al. Relapses and Recurrences in Giant Cell Arteritis. Medicine. 2011;90(3):186-193.

[2] Kim H, Lee J, Ha Y, Kim S, Lee C, Choi H et al. Induction of Remission is Difficult due to Frequent Relapse during Tapering Steroids in Korean Patients with Polymyalgia Rheumatica. Journal of Korean Medical Science. 2012;27(1):22

Disclosure of Interests: Mansi Bhurani: None declared, Stephen Hall Grant/ research support from: Abbvie, UCB, Janssen, Merck, Andrew Ostor Consultant of: MSD, Pfizer, Lilly, Abbvie, Novartis, Roche, Gilead and BMS, Speakers bureau: MSD, Pfizer, Lilly, Abbvie, Novartis, Roche, Gilead and BMS, Andrew Gibson: None declared

DOI: 10.1136/annrheumdis-2020-eular.2421 